\title{
Content and bioaccessibility of carotenoids from sweet peppers (Capsicum annuum L.)
}

\author{
S. A. Aherne, L. O'sullivan, M. A. Jiwan, T. Daly and N. M. O’brien \\ School of Food and Nutritional Sciences, University College Cork, Cork, Ireland
}

Peppers are a rich source of carotenoids and are one of the top ten contributors to the dietary intake of the carotenoids lutein and zeaxanthin in both the Republic of Ireland and Spain ${ }^{(1)}$. Therefore, we determined the content and bioaccessibility of carotenoids from red, green and yellow sweet (Bell) peppers. Carotenoid bioaccessibility, which is defined as the amounts of carotenoid(s) that are available for absorption in the gut after digestion, is a good indicator of carotenoid bioavailability ${ }^{(2,3)}$.

Red, green and yellow peppers, which originated in Spain, were purchased from a well-known supermarket chain. All manipulations with the vegetables were performed under subdued (yellow) light to minimise carotenoid photodegradation. Each food was weighed ( 2 g), homogenised and subjected to an in vitro digestion procedure ${ }^{(2,3)}$ which simulated human gastric and intestinal digestion. Micelle fractions were isolated from digested samples by ultracentrifugation. Both undigested and digested samples were extracted twice using a solvent mixture of hexane, acetone and ethanol (2:1:1); and the carotenoid content of the samples was quantified by HPLC, as previously described $^{(2)}$. Bioaccessibility $(\%)$ is defined as the proportion of carotenoids present in the micelle fractions compared with that contained in the original food.

\begin{tabular}{|c|c|c|c|c|c|c|}
\hline & \multicolumn{6}{|c|}{ Sweet (Bell) peppers } \\
\hline & \multicolumn{2}{|c|}{ Red } & \multicolumn{2}{|c|}{ Green } & \multicolumn{2}{|c|}{ Yellow } \\
\hline & Mean & SE & Mean & $\mathrm{SE}$ & Mean & $\mathrm{SE}$ \\
\hline \multicolumn{7}{|c|}{$\overline{\text { Content }(\mu \mathrm{g} / 100 \mathrm{~g})}$} \\
\hline$\beta$-carotene & $5634.8^{\mathrm{g}, \mathrm{y}}$ & 277.2 & $1467.2^{\mathrm{r}}$ & 146.5 & $833.7^{\mathrm{r}}$ & 146.9 \\
\hline Lutein & 1411.5 & 256.1 & $2211.1^{y}$ & 183.2 & $753.4^{\mathrm{g}}$ & 119.3 \\
\hline Zeaxanthin & $741.7^{\mathrm{y}}$ & 130.3 & 322.9 & 47.9 & $282.1^{\mathrm{r}}$ & 73.4 \\
\hline \multicolumn{7}{|c|}{ Bioaccessibility (\%) } \\
\hline$\beta$-carotene & $6.2^{\mathrm{g}, \mathrm{y}}$ & 0.5 & $13.4^{\mathrm{r}}$ & 1.7 & $12.7^{\mathrm{r}}$ & 1.8 \\
\hline Lutein & 54.3 & 4.2 & $45.9^{y}$ & 4.5 & $63.7^{\mathrm{g}}$ & 4.8 \\
\hline Zeaxanthin & 87.6 & 17.9 & 66.2 & 10.3 & 76.5 & 9.6 \\
\hline
\end{tabular}

Values are means for four independent experiments. ${ }^{\mathrm{r}, \mathrm{g}, \mathrm{y}}$ Means with unlike superscript letters denote a significant difference between the peppers; one-way ANOVA, followed by Tukey's multiple comparison test; $P<0.05$.

Of the red, green and yellow peppers, the red variety contained greater amounts of $\beta$-carotene $(P<0.05)$ and zeaxanthin. The yellow peppers had the lowest carotenoid content. The green colour of green peppers is principally due to the presence of chlorophyll and to carotenoids typical of the chloroplast such as lutein. Likewise, in the present study, the green bell variety had more lutein than the yellow $(P<0.05)$ and red bell peppers. The bioaccessibility of $\beta$-carotene was significantly greater $(P<0.05)$ from both green and yellow peppers compared to their red counterparts. Lutein was more bioaccessible from yellow than red and green $(P<0.05)$ peppers. Our findings show that red, green and yellow sweet peppers have different carotenoid profiles. Furthermore, carotenoid bioaccessibility varied within and between the three pepper varieties. These data suggest that the location of each carotenoid within the food matrix and/or carotenoidcarotenoid interactions may influence the bioaccessibility of carotenoids.

This work was supported by Science Foundation Ireland (PI Award 04/IN3/B509).

1. Maiani G, Periago Caston MJ, Catasta G et al. (2009) Mol Nutr Food Res. 53, S194-S218

2. O'Sullivan L, Ryan L, Aherne SA et al. (2008) Nutr Res 28, 532-538.

3. Garrett DA, Failla ML \& Sarama RJ (1999) J Agric Food Chem 47, 4301-4309. 